\title{
Experiences Impacting the Quality of Life of Mothers of Children With Autism and Intellectual Disability ${ }^{*}$
}

\author{
Jenny Fairthorne \\ Telethon Kids Institute, University \\ of Western Australia, \\ Perth, Australia
}

\author{
Colleen Fisher \\ School of Population Health, \\ University of Western Australia, \\ Perth, Australia
}

\author{
Jenny Bourke, Helen Leonard \\ Telethon Kids Institute, University \\ of Western Australia, \\ Perth, Australia
}

\begin{abstract}
In order to identify factors affecting the quality of life of mothers of children with both autism and intellectual disability, the first author interviewed 16 mothers of affected 11-24 year olds and transcribed audio recordings of the interviews. The first two authors analysed the resulting texts using a hermeneutical phenomenological approach. Mothers described living with their child's challenging behaviours, adapting to the increased demands and resultant isolation as lowering their quality of life. They described how surviving had strong negative impacts on their health and relationships. A majority of mothers described rewards associated with their children.
\end{abstract}

Keywords: quality of life, autism, intellectual disability, mothers, qualitative

\section{Introduction}

Quality of life is a concept describing overall well-being and results from a complex interaction of health, independence, relationships, goals, and standards in the context of a person's environment (Centre for Participant Reported Outcomes, 2007). Autism represents a group of severe, chronic, lifelong, neurodevelopmental disorders, which are diagnosed by impairments in the areas of social interaction, communication, and repetitive behaviours or interests (American Psychiatric Association, 2002). Intellectual disability is characterized by an intelligence quotient of less than 70 and limitations in adaptive skill which are manifest before 18 years (Leonard \& Wen, 2002). About $70 \%$ of persons with autism also have intellectual disability (Leonard et al., 2011).

Since the 1980s, the prevalence of autism diagnosis has been increasing both internationally (Centers for Disease Control and Prevention, 2012) and in Australia (Nassar et al., 2009). Parents of children with autism have been reported to have poorer physical and mental health (Mugno, Ruta, D'Arrigo, \& Mazzone, 2007) and quality of life (Allik, Larsson, \& Smedje, 2006) than other parents. Furthermore, mothers of children with autism have been shown to have more compromised health than fathers (Allik et al., 2006), mothers of healthy children (Totsika, Hastings, Emerson, Lancaster, \& Berridge, 2011) and the mothers of children with other

\footnotetext{
*Acknowledgments: We gratefully thank the Autism Association of Western Australia and the mothers who participated in this study.

Jenny Fairthorne, MSc., MPH, Telethon Kids Institute, University of Western Australia.

Colleen Fisher, Ph.D., Professor, The School of Population Health, University of Western Australia.

Jenny Bourke, MPH, Senior researcher, Telethon Kids Institute, University of Western Australia.

Helen Leonard, MB BCh., MPH, Clinical Professor, Telethon Kids Institute, University of Western Australia.
} 
developmental disabilities (Griffith, Hastings, Nash, \& Hill, 2010).

Reasons for the impaired quality of life of mothers of children with autism are likely to be complex. Some have postulated a genetic basis for the increased prevalence of mental disorders (Bolton, Pickles, Murphy, \& Rutter, 1998). However, there are many external factors why mothers might have a lower quality of life. Children with autism have more challenging behaviours (Matson \& Rivet, 2008) than healthy children and challenging behaviours are associated with lower maternal quality of life (Bourke-Taylor, Law, Howie, \& Pallant, 2010). Other factors include poor levels of social (Boyd, 2002) and family support (Bitsika \& Sharpley, 2004) and an overall perception of stigma against their children (Green, 2003). Notably, all of these risk factors are potentially modifiable.

Mothers with a lower quality of life are more likely to relinquish the care of their child (Bendixen et al., 2011) and the public costs of caring for a person with autism are up to 8.5 times that of a person with no disability (Jacobson \& Mulick, 2000). Some research suggests that the healthy siblings of children with autism have more behavioural problems than siblings of children with no disabilities (Hastings, 2003) whereas others have described both advantages and disadvantages to the siblings of children with developmental disability disorders (Dyke, Mulroy, \& Leonard, 2009). Either way, these healthy children benefit from the improved well-being of their mothers (Miodrag \& Hodapp, 2010).

The effects on mothers of raising a child with autism with intellectual disability compared to those of raising a child with autism without intellectual disability or a child with just intellectual disability are likely to be different. For example, children with autism without intellectual disability, due to their higher level of functioning, have more independence in the community. Thus they are more open to bullying and accidents. Therefore, compared to other groups, the factors impinging on the quality of life of mothers of children with both autism and intellectual disability are likely to be different.

We believe that exploring the experiences impacting on the quality of life of mothers of children with autism and intellectual disability is a response to an important public health issue. It is a first step in the development of evidence-based interventions and services to improve mothers' quality of life and consequently their ability to care for all of their children. This could reduce the need for the community provision of expensive full-time residential care for persons with autism and intellectual disability as well as services for their potentially disadvantaged siblings. Therefore, the aim of this study was to identify factors which mothers of children with autism and intellectual disability perceive as impacting on their quality of life.

\section{Methods}

\section{Research Design}

In this qualitative phenomenological study, we were guided by the hermeneutic principles of Van Manen (1990) and Heidegger as described by Gadamer (2004). Methodologically, hermeneutic phenomenology is appropriate to explore the essential features of lived experience impacting quality of life for mothers of children with autism and intellectual disability within a social and contextualised world (Van Manen, 1990).

\section{Sample and Recruitment}

Sampling was purposeful, and through AAWA (the Autism Association ofWestern Australia), we recruited 16 mothers of 11-24-year-old children with autism and intellectual disability from suburban 
Perth. The child's diagnosis of autism was confirmed as this is necessary for a family membership of AAWA. The presence of intellectual disability was reported by the mother and checked by the first researcher using the type of school that the child attended (or had attended). We considered that mothers of 11-24-year-olds would have had many experiences affecting their quality of life. Participants were also required to have fluent English to enable a detailed and rich understanding of lived experience to be elicited through interview.

\section{Data Collection and Analysis}

Interviews lasted from 40-120 minutes and were one to one, semi-structured and addressed the experiences of the mothers in context. Interviews were audio-recorded, transcribed verbatim and at transcription, pseudonyms were assigned to mothers and other potentially identifying items to preserve confidentiality. Expletives were moderated. Data were analysed by giving full consideration to the parts and the whole through a reflective back and forth process between analysis and writing akin to Heidegger's hermeneutic circle (Gadamer, 2004). As such, transcripts were read in their entirety several times by the first author, followed by a close, line by line reading to identify significant statements or horizons of experiences pertaining to quality of life. Significant statements were then clustered to form units of meaning. QSR NVivo10 facilitated storage, management, analysis and interrogation of data.

The first two authors discussed the units of meaning to ensure they were essential to the experience of impacted quality of life and further abstracted them to form themes. This ensured a rigorous analysis of the data. Hence, we extracted multiple meanings of the mothers' quality of life experiences (Van Manen, 1990) and were able to elucidate the universal essence of the factors impacting it (Cohen, Kahn, \& Steeves, 2000). Rigour was further enhanced by the maintenance of an audit trail of decisions made during data collection and analysis. We obtained ethical approval for this study from The University of Western Australia Human Research Ethics Committee (RA/4/1/6107).

\section{Results and Discussion}

\section{Participants and Their Children}

Characteristics of the 16 mothers and their 17 children are displayed in Table 1.

Of the 17 study children, there were 11 boys and six girls. Nine of them had functional language. Using the traits of functional language, type of school attended and mothers' descriptions, we categorized the child's level of functioning within this disability group. Seven were assessed as low functioning, four medium and six high. Although these distributions are not reflective of proportions in the general population, these children functioned across the range of levels found in persons with autism and intellectual disability.

Characteristics of the 16 mothers and their 17 children are displayed in Table 1.

We identified three multi-dimensional themes as essential to the experience of living with a child with autism and intellectual disability and impacting on the mothers' quality of life. These were:

(1) Living with the traits of the child's disability;

(2) Adapting to a new lifestyle ;

(3) Surviving challenges and savouring rewards.

Despite being intertwined in complex ways, we present these themes discretely for clarity (see Figure 1). 
Table 1

Characteristics of Mothers and Their Children With Autism and Intellectual Disability

\begin{tabular}{|c|c|c|c|c|c|c|c|c|c|}
\hline $\begin{array}{l}\text { Mother's } \\
\text { name }\end{array}$ & Age & $\begin{array}{l}\text { Current } \\
\text { marital } \\
\text { status }\end{array}$ & $\begin{array}{l}\text { Child's } \\
\text { name with } \\
\text { autism \& ID }\end{array}$ & $\begin{array}{l}\text { Mother } \\
\text { employed }\end{array}$ & $\begin{array}{l}\text { Age } \\
\text { gender } \\
\text { of child }\end{array}$ & $\begin{array}{l}\text { \& No. of children } \\
\text { with autism in } \\
\text { family }\end{array}$ & $\begin{array}{l}\text { Child verbal } \\
\text { (Yes/No) }\end{array}$ & $\begin{array}{l}\text { Child's level } \\
\text { of functioning }\end{array}$ & $\begin{array}{l}\text { Child living at } \\
\text { home (Yes/No) }\end{array}$ \\
\hline Amelie & 54 & Divorced & Guillaume & Yes & $20 \sigma^{\lambda}$ & 1 & No & Low & No \\
\hline Catherine & 46 & Divorced & Michaela & Yes & 13 우 & 2区 & No & Low & Yes \\
\hline Christa & 50 & Married & Caterina & Yes & $24 ㅇ$ & 2区 & No & Low & No \\
\hline Coby & 53 & Married & Samson & Yes & 17 え & 1 & No & Low & No \\
\hline Elise & 45 & Divorced & Jack & No & $11 \sigma^{\pi}$ & 1 & Yes & High & Yes \\
\hline Jane & 49 & Single & Faith & No & 11 우 & 1 & Yes & High & Yes \\
\hline Joanne & 50 & Married & $\begin{array}{l}\text { Aidan, } \\
\text { Caitlin }\end{array}$ & Yes & $\begin{array}{l}14 \text { o, } \\
12 \text { 우 }\end{array}$ & 2 & Yes, no & Medium, low & Yes, yes \\
\hline Kirsty & 48 & Single & Scarlett & Yes & 11 우 & 1 & No & Low & Yes \\
\hline Kylie & 42 & Married & Justin & No & 19 え & 1 & Yes & High & Yes \\
\hline Nadia & 55 & Remarried & Craig & No & $19 \widehat{~}$ & 1 & No & Low & No \\
\hline Patrice & 50 & Married & Dimitria & No & 17 우 & 1 & Yes & Medium & Yes \\
\hline Philippa & 48 & Married & Angus & Yes & $20 \widehat{\partial}$ & 1 & Yes & Medium & No \\
\hline Roslyn & 63 & Divorced & Edward & No & $17 \widehat{\partial}$ & $3^{*} \otimes$ & No & Medium & Yes \\
\hline Sharon & 50 & Remarried & David & Yes & $19 \widehat{\sigma}$ & 1 & Yes & High & Yes \\
\hline Tracy & 42 & Married & Jake & Yes & $11 \sigma^{\pi}$ & 1 & Yes & High & Yes \\
\hline Victoria & 42 & Married & Finlay & No & 110 & 1 & Yes & High & Yes \\
\hline
\end{tabular}

Notes. ID, intellectual disability; $\partial^{\lambda}$, male; + , female; autism, autism spectrum disorder; ${ }^{*}$ Includes 1 grandchild with autism; 区 Includes a child with autism without intellectual disability.

\section{MOTHER'SQUAUTY OF UFE}

\section{UVNG WITH THE TRAITS} OF THECHIL'SDISAEUTY

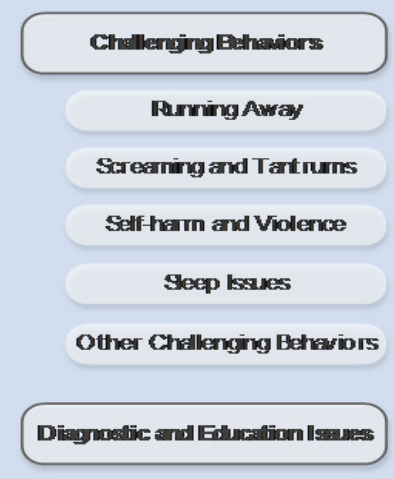

\section{ADAPTING TO A} NEN UFESTYLE

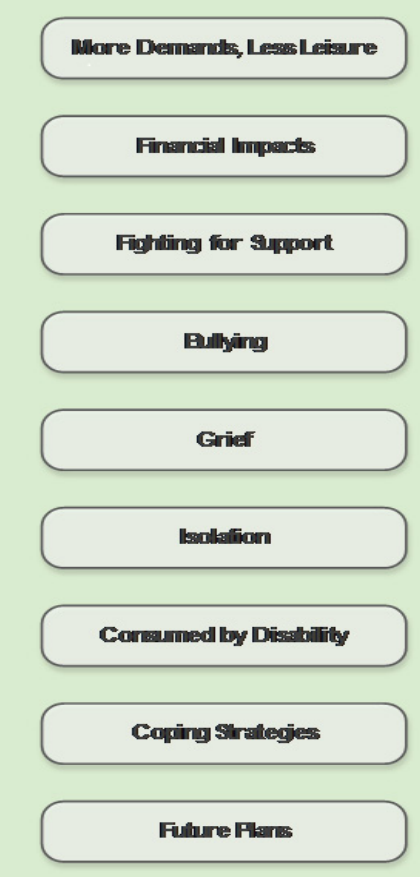

Figure 1. Themes and dimensions.

\section{SURMVNG CHAUENGES} AND SAVORNG REN ARDS

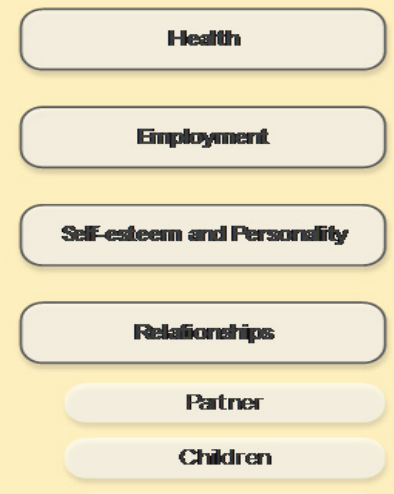

Extended Fanily and Friends Commurity Raneards 


\section{Living With the Traits of the Child's Disability}

Living with the traits of the disability of a child with autism and intellectual disability provides immediate challenges to parents and, longer term, can be very taxing. Compared to healthy children and children with other disabilities, children with autism and intellectual disability present more challenges to mothers in most areas of child rearing. These include toilet training (Cicero \& Pfadt, 2002), life skills (Smith \& Belcher, 1985), socially appropriate behaviours (Baker-Ericzén, Brookman-Frazee, \& Stahmer, 2005), challenging behaviours (Bailey, Golden, Roberts, \& Ford, 2007), sleep routines (Doo \& Wing, 2006) and communication skills (Koegel \& Kern Koegel, 2006). Each mother described how her child's disability traits had impinged on her quality of life.

Challenging behaviours. At interview, mothers described challenging behaviours in their children, including running away, screaming, tantrums, self-harm, violence, and sleep issues. These behaviours had impacted negatively on their quality of life.

Running away. A child's propensity to run away had major effects on quality of life and generated stress over safety concerns, foiled attempts to secure their properties and by limiting their life styles. For example, Nadia's son Craig went missing because a visitor left the gate open. She reported:

He was gone and he's a quick mover so I phoned the police. A detective came and picked me up in a police car. They even had the chopper out. Craig has no road sense at all. This was real panic stuff.

Elise recounted how Jack used to just "disappear":

He (Jack) disappeared down the shops... crossed the main road. I just about freaked out.

Screaming and tantrums. Mothers reported that screaming and tantrums occurred when the child did not get his/her own way, when routine was interrupted and sometimes for no ascertainable reason. These behaviours reduced quality of life because of stress, limitation of lifestyle or criticisms from by standers. Coby recalled a day when she was shopping with four-year-old Samson.

I strapped him into his stroller... There was a queue. In the end, he was so crazed, he was standing up strapped to his stroller and I kept saying, "Sam, sit down". He just got my hair and just was yanking. I whacked down on his arms this time because I had had a gutful... And there was a guy with his perfect twins in their perfect pram sitting there. And he said, "I don't believe what I just saw". I was like with scratches, bleeding... And he said, "You're a dinosaur lady. Who does that to their kid?".

Kirsty recounted how Scarlett's tantrums ruled their lives.

She was so distressed at the Wiggles finishing that it took me over an hour to get her out of the Entertainment Center... She almost pushed me over the balcony... We had all of management around us with walky talkies trying to get her out of the arena. They got her a wheel-chair and they strapped her in. They were stopping traffic so that I could go and get my car to come in a hurry to get her into the car. And the whole time she's kicking and screaming.

Kylie recalled:

If Justin wasn't used to the thought of going to a particular place, he'd kick up, tantrum and scream, "Not going”. So we'd end up not going.

Self-harm and violence. Self-harm and aggression have been identified in about half of people with autism (Billstedt, Gillberg, \& Gillberg, 2005). This can range from mild, such as gentle head banging, to severe 
which might include self-biting and violent head banging (Weiss, 2002). Christa, Joanne, and Nadia reported varying degrees of head banging in their children. Christa described how Caterina would scream while banging her head on the wall. Joannere called how Caitlin used to head butt a wall until her head bled and then play with the blood. Nadia told of the time Craig hit his head so hard against a wall that the plaster on the other side fell off. Apart from concerns from regarding injury, these behaviours lower a mother's quality of life by limiting her child's involvement in school and community activities (Matson \& Nebel-Schwalm, 2007).

A quarter of the mothers in this study reported extreme violence in their child which placed the physical safety of those around them at risk. Amelie told of Guillaume's violence at six years:

He smashed the whole house, the windows everything. I had the police...

Philippa reported:

Angus wasn't violent until he was about ten or eleven and it was hormonal, puberty. He got very violent. He would bite, scratch, pull your hair out by the handful, smash furniture and smash windows.

The mothers who experienced extreme violence found it the most intolerable of their children's challenging behaviours. Aggressive behaviours such as self-harm and violence have the greatest negative impact on caregivers and are the strongest predictor of parental stress (Hodgetts, Nicholas, \& Zwaigenbaum, 2013). So while parents find that extreme violence is the most challenging disability trait, reports indicate there are fewer resources for them in terms of available treatments or residential facilities for their children (Gray, 2002).

Sleep issues. A majority of mothers reported extended periods of sleep deprivation and the negative impact on quality of life. For instance, Elise reported that Jack would never settle to sleep. Similarly, Victoria described how she and her husband "lived off very little sleep". They coped with Finlay's night time wakefulness by sleeping in shifts with one sleeping from 7:30 pm to midnight and the other taking over Finlay's supervision from midnight.

Other challenging behaviours. Destructive behaviours were problematic because they isolated the family socially, increased workload and expenses and were upsetting. For example, Nadia said sadly of Craig:

He destroyed the beautiful things in our lives. I bought a rose to plant and he destroyed it.

Out in the community, Patrice's daughter, Dimitria would command her mother's attention by making louder and louder noises. This would severely limit Patrice's ability to informally chat with friends and others. Socially unacceptable behaviours such as this are stressful and ultimately isolating (Seltzer et al., 2010). Tracy reported that Jake (11) liked young girls of six or seven and added:

This is to do with his sexuality. In parks, he'll just go up and start playing and try to give them piggy backs.

Consequently, on family outings, Tracy and her husband were unable to relax and interactions with others were limited because they had to constantly monitor Jake's behaviour.

Diagnostic and education issues. Nearly half of our participants described diagnostic issues. Amelie reported that she "died inside" when the doctor said to her three times that there was no hope for her then three-year-old son Guillaume. Some mothers had to push for a diagnosis. Coby described how the paediatrician would not diagnose Samson because he was only 17 months old. To secure a diagnosis, she would just go and sit in the waiting room of his practice. Coby would show copies of reports to the paediatrician whenever he 
emerged and tell him that these provided evidence that her son had autism. Within a month, Coby had the diagnosis and she said:

I think autism was a great diagnosis for him (Samson). It meant that we had a starting point (for research, therapies and services).

Prior to a diagnosis of autism in their child, parents have expressed feelings of guilt, helplessness and ignorance (Siklos \& Kerns, 2007). Some wait years and with a diagnosis, they are both relieved and distressed. Commonly, parents are instructed to wait and see how their child develops. This is stressful and upsetting, especially if they are aware that early intervention might improve the prognosis of their child (Siklos \& Kerns, 2007).

Despite a large body of research identifying suitable educational practice for children with autism, little had been adopted by schools in U.S. (Iovannone, Dunlap, Huber, \& Kincaid, 2003). In Canada, the education system for children with autismis difficult to access and inadequately resourced (Woodgate, Ateah, \& Secco, 2008). Mothers in this study described difficulties which they found affected their quality of life. In Western Australia, students with autism are catered for in separate "Special Schools", "Education Support Units" within mainstream schools and in mainstream classes with an aide. Christa said:

I don't think Special Schools really know how to cater for autism... When she (Caterina) started screaming, they would just lock her up in a room. My husband went there (school) a couple of times and told them off. He could hear her screaming from the street.

When Dimitria was about six, Patrice recalled how frustrated and disrespected she felt at the teacher's inappropriate response when Dimitria put her hands down her pants in front of the class and then proceeded to put her hands in her mouth.

She sent me a letter! That was a real low in my life.

\section{Adapting to a New Lifestyle}

All mothers described lifestyle changes. Caregiving increased, expenses escalated, many fought for services and some experienced bullying or witnessed the bullying of their child. Mothers grieving their child's autism became increasingly isolated and some felt consumed by the disability. Dreams had been destroyed and future plans were now uncertain. Mothers developed a range of coping strategies.

More demands, less leisure. The increased caregiving demands and subsequent reduced leisure of parents of children with autism is identified in the literature (Tomanik, Harris, \& Hawkins, 2004). In this study, all mothers battled to adjust to this change. For example, four mothers learned ABA (Applied Behaviour Analysis) which uses positive reinforcements to improve children's behaviour (Francis, 2005). With children with autism, this involves a one-to-one relationship with a therapist who conducts repeated trials. For example, the therapist lines up different coloured cups on a table and instructs the child to "Give me red". Successful completion of tasks results in intermittent rewards for the child such as a sweet or a glimpse of a flashing light. This is time-consuming for a mother because often she has multiple roles in her child's ABA program which might run for up to 40 hours a week. For instance, the mother might be one or more of therapist, program developer, trainer and employer of other therapists, shift manager, and paymaster.

The four mothers, who ran a program at their home, reported their increase in workload. Coby said: 
You can't do it (run an ABA program). I burnt myself stupid. I was so thin and just didn't eat. I was awake all night, never slept. I was a bloody mess.

Researchers report the negative maternal impact of an ABA program just as these four mothers did (Schwichtenberg \& Poehlmann, 2007). Furthermore, the words of Coby humanize their finding that program intensity was inversely correlated with maternal well-being.

Mothers described the extra supervision required for their child. To supervise Faith in a playground, Jane would have to be constantly vigilant and always prepared to instantly chase and restrain her. She contrasted this to the more sociable and relaxing scenario for parents of healthy children by saying:

Most other parents sit down and talk while their kids play.

Mothers were regularly called to their child's school. Kylie noted:

I was always called up to the school (kindy) a couple of days a week. He (Justin) was not doing what he was told and he would just run amuck... at primary school it got worse.

There was no leisure for some of the mothers, even with grown children. Christa's children were Fabia (25), Caterina (24 with autism and intellectual disability) and Anna (19 with autism without intellectual disability). Her response when asked about leisure was:

What leisure? There was no spare time when Caterina was home and there's no leisure time now either.

Financial impacts. Families with a child with developmental disabilities have increased financial stress (Singhi, Goyal, Pershad, Singhi, \& Walia, 1990) with increased costs due to therapeutic and medical expenses (Sharpe \& Baker, 2007). Nadia recalled the high cost of early intervention, therapists and psychiatrists. Roslyn commented:

It's killed us financially because of all the money's been spent on the therapy... and there's no extra money ever for anything much.

Fighting for support. Adapting to lives with their children with autism and intellectual disability often involved battles with personnel whose employers were allocating supports. Sometimes this took many hours over months or years. This, combined with the ignorance, rudeness and lack of respect of some staff, can have a major and negative effect on parents' quality of life (Woodgate et al., 2008). Jane harassed the principal at Faith's school to request more aide support from the Education Department. Two mothers won additional support because they persisted with appeals against decisions made by government departments or sought the support of people in high positions. It took Victoria two years to receive therapy from a government agency. Weekly requests by phone to the agency made no difference. Then, Victoria met the State Premier and asked him why older children were not allocated services. He urged her to contact him if this continued. She did and within a week, the agency had found a place.

Joanne had three children with a disability. Their first had a physical disability and their second and third had autism with intellectual disability. Their third appeal at a social security claims tribunal for a Carer's Pension was rejected because the family's needs were not considered profound. At the fourth, Joanne and her husband finally gathered the strength to tell of their trials publicly and they won.

Bullying. Bullying impacted on the quality of life of the mothers of higher and medium functioning children. Jack's mother was distraught when a child put a video on You Tube disrespecting Jack and his family. Kylie 
reported that her son did not like being in mainstream because the students in mainstream classes always picked on him and called him an "idiot kid". Roslyn described how a mainstream classmate had taught Edward to masturbate under the desk at the back of the classroom. Notably, bullying was not discussed by mothers of low functioning children, perhaps because their children were more closely supervised. Although other researchers report that children with autism are at an increased risk of bullying (Humphrey \& Symes, 2010; Montes \& Halterman, 2007), we have added depth to this finding through identifying that children's experiences might be influenced by their level of functioning.

Grief. Mostly, mothers related their grief to a loss. They described losing their expected healthy child to autism. Joanne explained:

It's like grieving the death of the children we should have had. And for many, many years I struggled with it...

Roslyn consistently grieved for the loss of Edward's future. Parents of a child with intellectual disability also describe their on-going grief for the loss of the expected healthy child (Bruce, C. Schultz, Smyrnios, \& N. Schultz, 1994).

Isolation. Parents of children with autism isolate themselves socially because of their child's disruptive behaviours (Woodgate et al., 2008). Isolation also impacted heavily on these mothers' quality of life and increased with time while living with their child. Due to Craig's self-harming and aggressive behaviours, Nadia no longer went out socially, visited people or had friends. Patrice, Jane, Christa, and Nadia described a "shrinking" world with Patrice commenting:

You feel like you're becoming a hermit in a way because it (coping with Dimitria) just gets too hard as well. It just gets way too hard, even to go to church.

Consumed by disability. Some parents of children with autism miss a "normal" way of life because of the heavy load associated with their child's care (Woodgate et al., 2008). Likewise, the majority of mothers in this study alluded to a life-style which had evolved in response to their child's disability. Jane believed that there was more pressure on the parents of children with autism than that on the parents of children with Down syndrome (say) because there were numerous books and reports of children recovering from autism. By contrast, with Down syndrome, the chromosomal abnormality, essential for diagnosis, was always going to be there, regardless of therapies tried. Jane explained:

There are books like the Catherine Maurice one which says, "You can recover your child". So you've got this enormous pressure to do like 40 hours of therapy (a week).

For others, the enormous focus on their child's disability had practical origins due to the care-giving burden. Nadia and Elise described how their sons consumed their lives. Nadia considered that Craig had taken over her whole being. Elise explained how a family holiday at a local resort was cut short because Jack screamed continually and added:

He took up my whole, entire life.

Coping strategies. All mothers developed strategies to accommodate their new demands. Some, such as Catherine and Amelie chose escape mechanisms. Catherine confided:

I'm an alcoholic and a drug user. It's probably the only thing that gets me through. And I do. I come back here (home) at night and get drunk. 
Amelie viewed home as a haven and rationalised:

We couldn't go out because of Guillaume's wanting to touch the DVD, press the things ...so it was safety at home.

Others adopted positive coping strategies. In the community, when people stared, Philippa coped by explaining pleasantly:

That's autism. It's just what he does.

Out shopping, Victoria's son was often distraught. In order to stifle the potential comments of gawking bystanders, she would say:

Have you got a problem with my child? Ask me about autism.

Many mothers coped by planning their life around their child's disability. For example, Philippa planned family events closely around 20 year-old Angus and Nadia bought a house which met Craig's needs and not necessarily those of others in the family. Coby recounted another positive coping mechanism. She made the decision to be very unemotional when talking to professionals about her son and acknowledged:

If I let myself get emotional with one of these people and with one of their questions, I thought the flood-gates are going to open and I'm never going to be able to get myself back from it.

We found no research recognising Coby's method of coping. Her mechanism of shifting to cold affect, with little visible emotion, might be largely unrecognised by researchers and clinicians. Instead, it might be seen as intrinsic to the mother's personality.

Future plans. Mothers' futures were changed extensively by their children's disability. More than half considered that they would eventually have their own lives. For example, Amelie said:

I need to have a dream... It's changed but I can still have a life for myself.

Others considered the focus of their lives would always be their child with autism and intellectual disability. Sixty-three year old Roslyn had two children with autism and is a primary caregiver of her three-year-old grandson with autism. She said:

Well, my life really has been my children and keeping my home together and I don't see that that's going to change.

Catherine conveyed acceptance.

I don't worry about my life anymore. What's done is done.

These findings are new. While research was found examining life plans for people with autism (Schroeder, LeBlanc, \& Mayo, 1996), the perspective of mothers' futures was unexplored.

\section{Surviving Challenges and Savoring Rewards}

Many mothers recognised that they were battling to survive the challenges. As with any warfare, there were casualties and here they were poorer health, relinquished employment, lowered self-esteem, guilt, perceived personality change and altered relationships. With survival, mothers experienced rewards associated with their child's disability and because of their paucity, these rewards were savored.

Health. Mothers of children with autism have poorer overall well-being compared to mothers of healthy children (Khanna et al., 2011). Our data provided insight into the lived experience underlying previous research. 
Mothers described mental health issues which included depression, breakdowns and attempted suicide. Most considered that their poorer mental health was a direct result of the stress of parenting their child.

Jane recognised that she had a mental health issue and described an altered state where she felt "apart from her body". Catherine reported a nervous break down. Other reports of stress and depression were common with Amelie recalling:

With Guillaume, it (daily life) was so stressful. We just survived.

Sharon related depression to her general health and concluded:

Depression, big depression...To try and stay positive is the hard part... And when you're depressed, when you're down on yourself, anything can attack you... Your complete health (mental and physical) goes down the tube.

This association of mental and physical health is described extensively in the literature (Salovey, Rothman, Detweiler, \& Steward, 2000).

Some mothers had thoughts of ending their lives. Joanne related:

I was suicidal most of the time, even going to work every day... I thought, I could just go and drive my car into the ocean... and I felt like that most days because there was no end to this misery.

Only Amelie, acknowledged a suicide attempt. With no money or care for her son, she rang a community help line, ended up in hospital and was supplied with a government owned home and care for her son.

Physical health issues can result from chronic stressors (Miodrag \& Hodapp, 2010). Mothers reported a range of physical health issues and some considered the genesis was related to the stress of caregiving. Coby underwent a hysterectomy and Nadia described severe migraines, high blood-pressure, cholesterol, arthritis and a hip replacement. Philippa had suffered breast cancer and very high levels of the stress hormone cortisol which she attributed to the stress levels associated with caring for her child. She explained:

I've had breast cancer. It's (breast cancer) definitely linked because my cortisol levels were really high... There is a causal link with cancer and elevated levels of cortisol.

Employment. Outside employment can be protective in supporting the quality of life of mothers of children with developmental disabilities (Laurvick et al., 2006). Likewise, some mothers in this study recognised that employment aided their survival because it provided respite from their children and opportunities to interact in the outside world. Joanne said:

I got a job two days a week at Dudley Park Hospital, just to keep myself sane.

On the contrary, it was often difficult for mothers to work. Philippa remembered saying to herself:

You can't do this (work as a lawyer) with Angus. You have to stop. I'm so glad I got it (breast cancer)... I stopped and you have to because you're going to have a nervous breakdown (if you keep working).

Coby explained the impossibility of reconciling her caregiver and employment responsibilities because employers would be unlikely to accept her, saying (for example):

Sorry, I've got to go now, Samson's had a seizure.

Sharon recalled how her return to part-time work was aborted because the child care center did not cope with David's behaviour. In line with these mothers' comments, researchers cite some of the causes of lower 
employment of mothers of children with autism as the difficulties associated with accommodating all of child care issues, carer and employee responsibilities (Parish, Rose, \& Swaine, 2010).

Self-esteem and personality. Parenting a child with autism can obscure a parent's other sources of identity (Gray, 1993). In such a way, Joanne felt that she had lost her personal identity due to having children with special needs. Mothers acknowledged their lowered self-esteem and many attributed this to guilt. Catherine said:

What did I do wrong?... I blamed myself initially (for my two children's autism).

Personal guilt has been linked to lower self-esteem (Weiner, 1985) and increasing levels of guilt are associated with higher levels of anxiety in mothers of children with autism (Foody, James, \& Leader, 2014).

Nearly half of mothers perceived personality changes since the onset of their child's autism. Amelie reported how she gradually lost the opportunity to function independently as Guillaume's autism developed. Jane believed that her daughter's autism had put "bad grooves in her personality". Catherine recalled how she used to enjoy planning for the future but now she didn't bother and added:

I find that my personality has changed too. I used to love fun and love to get with people and have a great time.

We are the first to report self-perceived personality changes in the mothers of children with autism. However, there are reports of milder autistic traits related to anxiety and sociability in the first degree relatives of autistic probands (Piven, 1999). Perhaps, because of some researchers lack of contact with parents caring for a child with autism, this association is attributed entirely to genetics with no allowance for the pressure and constraints of caregiving.

Relationships. Mothers described the negative effects of their child's disability on family relationships, their healthy children and friendships. In the community with their child, many suffered ignorant and negative judgements. In combination, these effects reduced the mothers' quality of life.

Partner. Some mothers described their spouse's rejection of their child with autism and intellectual disability. Nadia reported that her former husband, David, rejected Craig completely because of his autism. She said:

After the marriage breakdown, he (David) would come over with Christmas presents for the other two (children) but nothing for Craig.

Several mothers reported less severe rejections, and possibly in relation to the difficult domestic situation rather than the child per se. Amelie's former husband would physically and emotionally isolate himself in his study, and ignore his wife and daughter's cries for help.

Those whose marriages disintegrated after the birth of their children with autism and intellectual disability, believed that the disability was a major contributing factor. Elise explained it like this.

Jack (son with autism) took away any time I had to give to my other children and husband, any quality time. That was it! It (the marriage) was over.

These findings provide new insight into the effect of autism and intellectual disability on the relationship between parents and the difficulty of some fathers in adapting to a life with their child with a disability. In some, this could be related to their belief that their wives caused their sons' autism. In this regard, Amelie said:

His father (her son's), the whole family, went against me. Everybody said that I was the problem. 
In a similar vein, Sharon recalled her husband saying that she was the cause of her son's problems. This is the first research to describe paternal reactions to their children with autism and intellectual disability and resultant family situations. We found only one recent report (Dababnah \& Parish, 2013) of a husband who blamed his wife for their child's autism. Descriptions from parents of a child with ADHD (attention deficit hyperactivity disorder) reflect a similar perspective that described by mothers in this study. For example, some fathers of boys with ADHD perceived that their wives' mothering styles might be encouraging behavioural problems. In a similar way to some partners of women in this study, fathers left their wives to tackle the child's problems alone (Singh, 2004).

Children. Consistent with previous research (Hastings, 2003), mothers in this study indicated disadvantages to their children without disability. This was another source of stress which again impacted on the mothers' quality of life. Mothers relayed how their children with autism and intellectual disability were usually the focus of attention, leaving their siblings with little. For example, Guillaume's ABA therapists were in the home for dozens of hours a week. They totally focused on Guillaume and lavished him with attention and praise. In comparison, his younger sister, Rebecca, had little praise and had to teach herself many life skills such as toileting and eating with a spoon. Coby described how Brittany fretted because her younger brother had ABA and she would wail:

Why can't I have ABA? I want ABA.

Philippa used to cue people into Angus's condition by saying that Angus was special because he had autism. When, his older brother, Samuel was about seven, he said to his mother despondently:

You never tell anybody that I'm special.

Other mothers described how their healthy children saw their siblings with autism and intellectual disability as being the mother's favourites. Kylie's healthy children accused her of favouring Justin. Similarly, Tracy reported Jake's younger siblings as complaining that Jake got "so much".

Limitations to family activities were problematic, particularly for siblings. Nadia described how Craig's autism affected the family's quality of life.

We go to the beach. Craig loses it, so we have to pack up and come home. So we don't go to the beach anymore.

Similarly, Roslyn recalled how they could not go to the movies or to dinner because of Edward's inability to cope and summarized by saying:

It (Edward's disability) has impacted every... every part of our family life.

Special arrangements were necessary for friends of healthy siblings to visit. In relation to Dimitria's older sister and boy-friends, Patrice said:

When young boys started coming here (to see Dimitria's sister), I'd know to keep Dimitria, sort of away, type of thing because it is embarrassing, having to explain (Dimitria's behaviour) while Dimitria's jumping around and her breasts are flying all over the place.

Of Edward, Roslyn said:

He used to take his clothes off in front of visitors and they (his sisters) were very embarrassed and upset with his behaviour. 
Of the effect on Samuel of Angus's emergent violence, Philippa said:

Samuel would walk in the front gate (after school) and not know what conditions were behind the front door. Things might be fine or he might find his mother under attack.

Possibly, children who experienced violence from their sibling with autism and intellectual disability were the most traumatised. Amelie and Nadia spoke of how their child with a disability had attacked his siblings. Amelie remembered how Guillaume assaulted Rebecca repeatedly.

She was always bruised, beaten, scratched... It was as though he wanted to kill her.

Nadia described an horrific incident when Craig was about seven and his brother, Rory, four. Craig knocked a carer down and then he went to strangle Rory.

Without a doubt, he (Craig) was trying to kill him, honestly kill him.

Guillaume's younger sister, Rebecca is now 17 and has made multiple suicide attempts and recently spent eight weeks in a psychiatric clinic. Coby's daughter Brittany is 21 and her mother reported that she has been troubled with behavioural issues throughout secondary school. Nadia's son, Rory is 17 and has oppositional defiance disorder. Any links to their childhood traumas can only be surmised. Other studies have reported mothers' descriptions of the negative effects on their other children in terms of the resultant pressure on these children to grow up too quickly, their lesser opportunities to socialise and their reduced attention from parents (Nealy, O'Hare, Powers, \& Swick, 2012). In contrast, in families with a child with Down or Rett syndrome, parents attributed increased tolerance, compassion and appreciation of their own health (Mulroy, Robertson, Aiberti, Leonard, \& Bower, 2008).

Extended family and friends. The attitudes of extended family varied from supportive; well-meaning but ignorant; estranged; or judgemental and damning. Almost half of the mothers in this study benefitted from helpful and supportive family members. Such family support is associated with improved outcomes in parents of children with a disability (Hassall, Rose, \& McDonald, 2005). Kirsty reported that, apart from a sister, her "family was cool with Scarlett" and they provided help by baby-sitting. For many years, Sharon's mother helped her regularly with her son. Mothers also reported ignorant but well-meaning relatives who had problems coping with aspects of the disability. For example, Patrice described her parents-in-law as believing:

If I take her (Dimitria) to church and she gets communion and that, it's all going to go away.

Philippa's mother-in-law was a former school teacher and lived in England. Shortly after Angus's diagnosis, she said:

I've shown a photograph of Angus to my neighbour and she's a psychologist and she said there's nothing wrong with him.

Sometimes extended family members sever connections because of a child's autism (Boyd, 2002). This was Catherine's experience and she reported:

My brother and his wife, never come near me...It's (my children's autism) embarrassing (for them).

Finally, other mothers described judgemental members of their husbands' families who blamed them for their children's autism. Amelie had the horrific experience of her husband's entire family blaming her for her 
son's autism. Christa's self-esteem had been negatively affected by her mother-in-law. She related how her mother-in-law would visit and say:

Your child should be like this. She should be toilet trained... It's your side of the family...She said "I wasn't mothering properly".

Historically, mothers have been blamed for their child's autism (Kanner, 1943). From some mothers' perspectives, this practice is continuing.

Improved outcomes in mothers of children with autism are positively correlated with both increased and perceived friendship support (Ekas, Lickenbrock, \& Whitman, 2010).

Mothers in this study experienced difficulty with retaining old friends and described the difficulty of instigating new friendships. For instance, Joanne spoke of her friends at the time of her children's diagnoses and said:

Some of the friends we made, we lost. We were never told the reason but we assumed they might have been scared off in case we asked them for help.

Amelie and Kirsty had neither the time nor energy to make new friends. Amelie said:

I didn't have a social life... It takes effort to make friends. You have to reciprocate... There was nothing that I could do apart from care for my children.

Kirsty explained how she had neither the time, energy nor the inclination to make friends.

The lowering of social support in mothers of children with autism, since the development of their children's disability, is described in the literature. These mothers have less social support than either mothers of children with intellectual disability or mothers of healthy children (Weiss, 2002) and the effect on their quality of life is likely to be considerable (Ekas et al., 2010).

Community. Unlike Down syndrome, children with autism are not recognisable by physical traits. Usually, people in the community are unaware that a child with autism has a problem until he or she behaves badly. The insensitive reactions of bystanders would likely be caused by ignorance and parents describe this ignorance as isolating (Woodgate et al., 2008). Such reactions include damning comments about the mother's parenting skills, inappropriate suggestions about dealing with the behaviour or blatant staring. A majority of mothers described upsetting experiences with their children in the community. Coby recalled negative comments directed at her when she had behaviour management problems with Samson. People would walk past her and say "Jesus!" in disgust. Of the wider community and her daughter's autism, Christa said:

They don't understand... I took her (Caterina, 12) to Bindajyne Shopping Centre... This kid had an ice-cream and we were passing. She grabbed this ice-cream from this kid. The mother came up to me and said, "Your kid stole my kid's ice-cream. Hasn't your kid got any manners?" I said, "Excuse me but my daughter has autism". She said, "I don't care". Then I said, "Look, I'll pay for the ice-cream". The husband came up and said, "Don't worry about it"... The other mother went on, "She should educate her child more".

Jane was upset by what she described as:

The total lack of fricking empathy and understanding in the community and the constant trying to explain and feeling like you are a mad person and the exhaustion and people expecting you to do more.

Some mothers suggested that negative interactions in the wider community most affected their quality of 
life. This might be a result of the persistent belief that parents, particularly mothers, cause their children's challenging behaviours (Altiere \& von Kluge, 2009).

Rewards. In spite of challenges, most mothers identified one or more personal rewards associated with their child's disability. Some spoke of their love for their child. Of Jack, Elise declared:

I love him. I love the spunk in his personality.

Some mothers consider that their personal development had been enhanced by caring for their child (King, Zwaigenbaum, Bates, Baxter, \& Rosenbaum, 2011). Along these lines, Amelie confided:

I feel blessed that I had Guillaume. I'm a better person.

Others described joy from their child's development. For instance, Catherine said:

Now Michaela has eye-contact which is really nice; especially when they look you in the eye and they are so sweet.

Many described the exceptional people whom they had met because of their child's disability. Roslyn spoke in superlatives of Edward's two classroom aides who had enabled him to attend his school's Annual Year 11 Dinner Dance. She said:

Two ladies in the Ed (Education) Support Unit, Mrs Robertson and Mrs Boyle, his two favourites, picked him up from home and brought him back. They're the most wonderful women on earth.

Other mothers related their increased appreciation of simple things. For example, Patrice recalled:

Having Dimitria has made me appreciate the simple things in life... like appreciating the naivety and the cheekiness of little kids sometimes.

Finally, mothers translated the possible benefits to others from their participation in this study into their own personal satisfaction.

\section{Limitations and Recommendations}

Mothers might have omitted factors affecting their quality of life due to a desire to protect their privacy, embarrassment or a belief that it was not relevant. Those struggling to cope might have been unable to respond to our invitation to participate. Hence, the demonstrated effects on quality of life could be incomplete and attenuated. Diagnostic and educational issues, family and community attitudes might vary in other countries. Also, all participants spoke fluent English and lived in the metropolitan area of a city of nearly two million people. Mothers in rural areas and mothers from culturally and linguistically diverse backgrounds might perceive different impacts on their quality of life.

Research is indicated to inform governments and agencies of evidence-based services and interventions likely to improve the overall quality of life of mothers of children with autism and intellectual disability. Modifiable risk factors, such as community and family ignorance and coping strategies affecting these women's quality of life might be targeted by interventions or services. For example, communities and extended families might be informed of autistic behaviours and parents' difficulties in their management. Conversely, parents might be provided with positive options to deal with ignorant and/or critical members of their families and the community. Further, research is implicated to explore the emotional and physical protection of siblings of children with autism and violent behaviour. 


\section{Conclusion}

In this study, mothers of children with autism and intellectual disability experienced a reduced quality of life. Few areas of their lives had been spared from the pervasive and negative effects of their children's disability. Living with disability traits, adapting to changed life styles and surviving the challenges left many with a lifestyle with little resemblance to its precursor. For some, careers were lost, marriages broken, social networks destroyed and health damaged. Nevertheless, most mothers reported rewards associated with their children with a disability. Some continued to see no future apart from their child. Others were able, or planned to emerge from this challenging period and build a future not wholly centred round their children with autism and intellectual disability.

\section{References}

Allik, H., Larsson, J., \& Smedje, H. (2006). Health-related quality of life in parents of school-age children with Asperger syndrome or high-functioning autism. Health and Quality of Life Outcomes, 4(1), 1-8.

Altiere, M., \& von Kluge, S. (2009). Searching for acceptance: Challenges encountered while raising a child with autism. Journal of Intellectual and Developmental Disability, 34(2), 142-152.

American Psychiatric Association. (2002). Diagnostic criteria for 299.00 autistic disorder.

Bailey, D., Golden, R., Roberts, J., \& Ford, A. (2007). Maternal depression and developmental disability: Research critique. Mental Retardation and Developmental Disabilities Research Reviews, 13(4), 321-329.

Baker-Ericzén, M., Brookman-Frazee, L., \& Stahmer, A. (2005). Stress levels and adaptability in parents of toddlers with and without autism spectrum disorders. Research and Practice for Persons With Severe Disabilities, 30(4), 194-204.

Bendixen, R., Elder, J., Donaldson, S., Kairalla, J., Valcante, G., \& Ferdig, R. (2011). Effects of a father-based in-home intervention on perceived stress and family dynamics in parents of children with autism. American Journal of Occupational Therapy, 65(6), 679-687.

Billstedt, E., Gillberg, C., \& Gillberg, C. (2005). Autism after adolescence: Population-based 13 to 22 year follow-up study of 120 individuals with autism diagnosed in childhood. Journal of Autism and Developmental Disorders, 35(3), 351-360.

Bitsika, V., \& Sharpley, C. (2004). Stress, anxiety and depression among parents of children with autism spectrum disorder. Australian Journal of Guidance and Counselling, 14(2), 151-161.

Bolton, P., Pickles, A., Murphy, M., \& Rutter, M. (1998). Autism, affective and other psychiatric disorders: Patterns of familial aggregation. Psychological Medicine, 28(2), 385-395.

Bourke-Taylor, H., Law, M., Howie, L., \& Pallant, J. (2010). Development of the Child's Challenging Behaviour Scale (CCBS) for mothers of school-aged children with disabilities. Child: Care, Health and Development, 36(4), 491-498.

Boyd, B. (2002). Examining the relationship between stress and lack of social support in mothers of children with autism. Focus on Autism and Other Developmental Disabilities, 17(4), 208-215.

Bruce, E., Schultz, C., Smyrnios, K., \& Schultz, N. (1994). Grieving related to development: A preliminary comparison of three age cohorts of parents of children with intellectual disability. British Journal of Medical Psychology, 67(1), 37-52. doi: 10.1111/j.2044-8341.1994.tb01769.x

Centre for Participant Reported Outcomes. (2007). About the WHOQoL (World Health Organisation Quality of Life) Project. Retrieved from http://www.psychiatry.unimelb.edu.au/centres-units/cpro/whoqol/resources/about_whoqol_project.pdf

Cicero, F., \& Pfadt, A. (2002). Investigation of a reinforcement-based toilet training procedure for children with autism. Research in Developmental Disabilities, 23(5), 319-331.

Cohen, M., Kahn, D., \& Steeves, R. (2000). Hermeneutic phenomenological research: A practical guide for nurse researchers. Thousand Oaks, California: Sage Publications Inc..

Dababnah, S., \& Parish, S. (2013). "At a moment, you could collapse": Raising children with autism in the West Bank. Children and Youth Services Review, 35(10), 1670-1678.

Doo, S., \& Wing, Y. (2006). Sleep problems of children with pervasive developmental disorders: Correlation with parental stress. Developmental Medicine and Child Neurology, 48(8), 650-655.

Dyke, P., Mulroy, S., \& Leonard, H. (2009). Siblings of children with disabilities: Challenges and opportunities. Acta Pcediatrica, 98(1), 23-24. doi: 10.1111/j.1651-2227.2008.01168.x 
Ekas, N., Lickenbrock, D., \& Whitman, T. (2010). Optimism, social support and well-being in mothers of children with autism spectrum disorder. Journal of Autism and Developmental Disorders, 40(10), 1274-1284.

Foody, C., James, J., \& Leader, G. (2014). Parenting stress, salivary biomarkers and ambulatory blood pressure in mothers of children with autism spectrum disorders. Research in Autism Spectrum Disorders, 8(2), 99-110. doi: http://dx.doi.org/10.1016/j.rasd.2013.10.015

Francis, K. (2005). Autism interventions: A critical update. Developmental Medicine and Child Neurology, 47(7), 493-499. doi: 10.1111/j.1469-8749.2005.tb01178.x

Gadamer, H. (2004). Truth and method. Continuum International Publishing Group.

Gray, D. (1993). Perceptions of stigma: The parents of autistic children. Sociology of Health and Illness, 15(1), 102-120.

Gray, D. (2002). Ten years on: A longitudinal study of families of children with autism. Journal of Intellectual and Developmental Disability, 27(3), 215-222.

Green, S. (2003). What do you mean "What's wrong with her?": Stigma and the lives of families of children with disabilities. Social Scence and Medicine, 57(8), 1361-1374.

Griffith, G., Hastings, R., Nash, S., \& Hill, C. (2010). Using matched groups to explore child behaviour problems and maternal well-being in children with Down syndrome and autism. Journal of Autism and Developmental Disorders, 40(5), 610-619.

Hassall, R., Rose, J., \& McDonald, J. (2005). Parenting stress in mothers of children with an intellectual disability: The effects of parental cognitions in relation to child characteristics and family support. Journal of Intellectual Disability Research, 49(6), 405-418. doi: 10.1111/j.1365-2788.2005.00673.x

Hastings, R. (2003). Brief report: Behavioural adjustment of siblings of children with autism. Journal of Autism and Developmental Disorders, 33(1), 99-104.

Hodgetts, S., Nicholas, D., \& Zwaigenbaum, L. (2013). Home sweet home: Families' experiences with aggression in children with autism spectrum disorders. Focus on Autism and Other Developmental Disabilities, 28(3), 166-174.

Humphrey, N., \& Symes, W. (2010). Perceptions of social support and experience of bullying among pupils with autistic spectrum disorders in mainstream secondary schools. European Journal of Special Needs Education, 25(1), 77-91.

Iovannone, R., Dunlap, G., Huber, H., \& Kincaid, D. (2003). Effective educational practices for students with autism spectrum disorders. Focus on Autism and Other Developmental Disabilities, 18(3), 150-165.

Jacobson, J., \& Mulick, J. (2000). System and cost research issues in treatments for people with autistic disorders. Journal of Autism and Developmental Disorders, 30(6), 585-599.

Kanner, L. (1943). Autistic disturbances of affective contact. Nervous Child, 2(3), 217-250.

Khanna, R., Madhavan, S., Smith, M., Patrick, J., Tworek, C., \& Becker-Cottrill, B. (2011). Assessment of health-related quality of life among primary caregivers of children with autism spectrum disorders. Journal of Autism and Developmental Disorders, 41(9), 1214-1227. doi: 10.1007/s10803-010-1140-6

King, G., Zwaigenbaum, L., Bates, A., Baxter, D., \& Rosenbaum, P. (2011). Parent views of the positive contributions of elementary and high school-aged children with autism spectrum disorders and Down syndrome. Child: Care, Health and Development, 38(6), 817-828.

Koegel, R., \& Kern Koegel, L. (2006). Pivotal response treatments for autism: Communication, social, and academic development. ERIC.

Laurvick, C., Msall, M., Silburn, S., Bower, C., De Klerk, N., \& Leonard, H. (2006). Physical and mental health of mothers caring for a child with Rett syndrome. Pediatrics, 118(4), 1152-1164.

Leonard, H., Glasson, E., Nassar, N., Whitehouse, A., Bebbington, A., Bourke, J.,... Stanley, F. (2011). Autism and intellectual disability are differentially related to sociodemographic background at birth. PloS one, 6(3), e17875.

Leonard, H., \& Wen, X. (2002). The epidemiology of mental retardation: Challenges and opportunities in the new millennium. Mental Retardation and Developmental Disabilities Research Reviews, 8(3), 117-134.

Matson, J., \& Nebel-Schwalm, M. (2007). Assessing challenging behaviours in children with autism spectrum disorders: A review. Research in Developmental Disabilities, 28(6), 567-579. doi: http://dx.doi.org/10.1016/j.ridd.2006.08.001

Matson, J., \& Rivet, T. (2008). Characteristics of challenging behaviours in adults with autistic disorder, PDD-NOS, and intellectual disability. Journal of Intellectual and Developmental Disability, 33(4), 323-329.

Miodrag, N., \& Hodapp, R. (2010). Chronic stress and health among parents of children with intellectual and developmental disabilities. Current Opinion in Psychiatry, 23(5), 407-411.

Montes, G., \& Halterman, J. (2007). Bullying among children with autism and the influence of comorbidity with ADHD: A population-based study. Ambulatory Pediatrics, 7(3), 253-257. doi: http://dx.doi.org/10.1016/j.ambp.2007.02.003 
Mugno, D., Ruta, L., D'Arrigo, V., \& Mazzone, L. (2007). Impairment of quality of life in parents of children and adolescents with pervasive developmental disorder. Health and Quality of life Outcomes, 5(22), 15-23.

Mulroy, S., Robertson, L., Aiberti, K., Leonard, H., \& Bower, C. (2008). The impact of having a sibling with an intellectual disability: Parental perspectives in two disorders. Journal of Intellectual Disability Research, 52(3), 216-229.

Nassar, N., Dixon, G., Bourke, J., Bower, C., Glasson, E., De Klerk, N., \& Leonard, H. (2009). Autism spectrum disorders in young children: Effect of changes in diagnostic practices. International Journal of Epidemiology, 38(5), 1245-1254.

Nealy, C., O'Hare, L., Powers, J., \& Swick, D. (2012). The impact of autism spectrum disorders on the family: A qualitative study of mothers' perspectives. Journal of Family Social Work, 15(3), 187-201.

Parish, S., Rose, R., \& Swaine, J. (2010). Financial well-being of US parents caring for co-resident children and adults with developmental disabilities: An age cohort analysis. Journal of Intellectual and Developmental Disability, 35(4), 235-243. doi: $10.3109 / 13668250.2010 .519331$

Piven, J. (1999). Genetic liability for autism: The behavioural expression in relatives. International Review of Psychiatry, 11(4), 299-308.

Salovey, P., Rothman, A., Detweiler, J., \& Steward, W. (2000). Emotional states and physical health. American Psychologist, 55(1), 110-121.

Schroeder, S., LeBlanc, J., \& Mayo, L. (1996). Brief report: A life-span perspective on the development of individuals with autism. Journal of Autism and Developmental Disorders, 26(2), 251-255.

Schwichtenberg, A., \& Poehlmann, J. (2007). Applied behaviour analysis: Does intervention intensity relate to family stressors and maternal well-being? Journal of Intellectual Disability Research, 51(8), 598-605. doi: 10.1111/j.1365-2788.2006.00940.x

Seltzer, M., Greenberg, J., Hong, J., Smith, L., Almeida, D., Coe, C., \& Stawski, R. (2010). Maternal cortisol levels and behaviour problems in adolescents and adults with ASD. Journal of Autism and Developmental Disorders, 40(4), 457-469.

Sharpe, D., \& Baker, D. (2007). Financial issues associated with having a child with autism. Journal of Family and Economic Issues, 28(2), 247-264.

Siklos, S., \& Kerns, K. (2007). Assessing the diagnostic experiences of a small sample of parents of children with autism spectrum disorders. Research in Developmental Disabilities, 28(1), 9-22.

Singh, I. (2004). Doing their jobs: Mothering with Ritalin in a culture of mother-blame. Social Science and Medicine, 59(6), 1193-1205.

Singhi, P., Goyal, L., Pershad, D., Singhi, S., \& Walia, B. (1990). Psychosocial problems in families of disabled children. British Journal of Medical Psychology, 63(2), 173-182.

Smith, M., \& Belcher, R. (1985). Teaching life skills to adults disabled by autism. Journal of Autism and Developmental Disorders, 15(2), 163-175.

Totsika, V., Hastings, R., Emerson, E., Lancaster, G., \& Berridge, D. (2011). A population-based investigation of behavioural and emotional problems and maternal mental health: Associations with autism spectrum disorder and intellectual disability. Journal of Child Psychology and Psychiatry, 52(1), 91-99.

Van Manen, M. (1990). Researching lived experience: human science for an action sensitive pedagogy. New York: State University of New York Press.

Wan, C., Bazen, L., Baars, R., Libenson, A., Zipse, L., Zuk, J.,... Schlaug, G. (2011). Auditory-motor mapping training as an intervention to facilitate speech output in non-verbal children with autism: A proof of concept study. PloS one, 6(9), e25505.

Weiner, B. (1985). An attributional theory of achievement motivation and emotion. Psychological Review, 92(4), 548-573.

Weiss, J. (2002). Self-injurious behaviours in autism: A literature review. Journal on Developmental Disabilities, 9(2), $127-144$.

Weiss, M. (2002). Hardiness and social support as predictors of stress in mothers of typical children, children with autism, and children with mental retardation. Autism, 6(1), 115-130.

Woodgate, R., Ateah, C., \& Secco, L. (2008). Living in a world of our own: The experience of parents who have a child with autism. Qualitative Health Research, 18(8), 1075-1083. 